The Geneva Papers on Risk and Insurance, 15 (No. 57, October 1990), 364-371

\title{
Third Geneva Lecture The International Strategy of European Insurance Companies*
}

\author{
by Enrico Randone**
}

I have the honour of speaking to you this evening on behalf of the Geneva Association. May I say how grateful I am to the Association for this privilege, as also for this opportunity to share with an influential assembly my thoughts on a subject of such importance.

To attempt a description of the international strategy of European insurance companies as they prepare for 1992 is at once an enviable and somewhat unrewarding task, especially now in this time of great change. We are witnessing today not only a vast restructuring of the European insurance sector, but also a thorough overhaul of the specific strategies of individual companies. Assessment of any new strategic decision reflecting aims which differ from one company or group to the next, will inevitably depend on the view point of the observer, or on the market position of the maker of the decision or of the person assessing it.

It would therefore be a little presumptuous of me to attempt to deal with this subject exhaustively. I shall however endeavour to identify certain overall trends and more especially to describe the strategy of the Group of which I am President : the "Generali". I venture to hope that the picture I provide will bring to light certain important issues which will stimulate our thinking on lines both useful and valid for the market as a whole.

The international strategy of European insurance firms as 1992 draws closer and especially in terms of what lies beyond that date must be examined against the more general but very complex backcloth of a globalisation process which has now acquired unstoppable momentum. The speed of information flow, the increasing mobility of persons, enterprises and activities of all kinds will cause the process now underway to flow out beyond the industrial goods sector to reach that of services and thence to insurance.

As the curtain rises on 1993 the centre-stage will be occupied by the Mega Markets (North America, Asia and Europe) and by firms of international standing eager to penetrate them. Such firms will be sensitive, I may add, to varying local needs and capable of managing complex systems and financial assets acquired from a variety of sources. 1993 will offer the spectacle of competition among Community enterprises within a single European Market. Through such competition, where they are adequately prepared, firms will gain access to international markets at the highest possible level.

* Held in Brussels, February 16, 1990, at the auditorium of the Royale Belge.

** President, Generali, Trieste. 
European firms will be facing competition not only from old-hands like the USA, Japan and certain already advanced Asian countries (Korea, Taiwan, Singapour, Hong Kong) but from some emerging competitors as well - Thailand, Malaysia and Indonesia. And it will not be long before yet other countries - China, India and the USSR - join the fray. For this very reason, European firms must take full advantage, and at all levels, of their "continental stature". To meet such changes, many insurance companies are already preparing adjustments which will give their operations an international dimension so as to be able to meet the needs of a clientèle which itself is becoming increasingly international.

Insurance companies, therefore, which would have a stake in this new economic venture must acquire sufficient stature so as to be able to operate internationally and must then go on to develop global strategies which will make subsequent growth possible. Even if the future seems to offer encouraging prospects for insurers anxious to expand their operations, growth on the domestic market will no longer suffice. The latter will need to be accompanied by international buy-outs, mergers, agreements and acquisitions, for national status alone, even if important locally, might well condemn a company to a secondary place in the Single Market and to virtually no place at all in the Global Market to come.

What strategy, then, should be adopted by a Community insurance company not content merely to play a national, regional or local role, or which wants to offer something more than a specialised service? There is no simple answer to this question.

Managements today have inherited from their predecessors specific situations which in some cases make the task in hand more easy, in others more difficult. Whatever the case, the development strategy of every firm will be a function of the situation it has inherited from its past. All firms, however, must remain aware of the absolute requirement to offer clients everywhere, at whatever cost, a service of the highest possible quality.

Growth will be especially promoted by consistency of approach and by choices which take due account of two main avenues of endeavour. The distinguishing features of the first of these avenues are technological progress in management, the capillary attraction of market presence, global product supply and refinement of the content of insurance coverage; the second avenue by contrast leads to ensuring professionalism and quality of service not merely in meeting clients' increasingly sophisticated demands - by supplying the right service at the right place - but also in being able to anticipate latent needs.

Companies will discover the enormous strategic advantages not only of innovation in the technological aspects of management, in product distribution and policy content (computerisation, alternative sales channels, new products) which represent the visible side of insurance work, but also of searching out opportunities for creating differentials in the less tangible domaine of product service; that is, in the domaine of invisible satisfactions (emotions, expectations, typical perceptions of human nature) which any enterprise can and should be offering its clientèle.

While technological innovation will continue to be more conspicuous, the real innovations influencing results will be the changes in behaviour at all levels. The aim here would be to ensure that, in the symbiotic product - service relationship, the user receives high quality. The challenge of 1992 will be sucessfully taken up by those firms which, while keeping abreast of technological developments, are able to pay particular attention to the search for "excellence" in human relations; of this I am utterly convinced. Consideration must be 
given to this point not only outside the firm or group but within them as well, so that all concerned whoever they may be are able to make a contribution to improving the enterprise-service and its product-service if a place of prestige on the market is to be secured.

Organisations must be able to offer a homogeneous quality of service, without which and this is true not only of the European context - they will be faced with grave problems in creating competitive advantages. It is therefore crucial that sufficient emphasis be placed upon the quality of personnel and of the work they provide; stress also must be laid on improving the quality of the work environment so as to maximise the quality of the productservice offered to the end-user.

The actual provision of a service to the world outside the enterprise, namely the moment of contact between the member of staff and the customer is the all-important moment of truth in the work of any insurance company since it reveals inexorably the latter's strenghts and weaknesses. The employee responsible for such contact must have as his or her priority not only the provision of the right service, but also a strenghtening of the bonds that link the customer to the company. It becomes essential therefore to seek out qualified personnel and then to enable them to function and blossom within a working environment where strategy and structure combine in a modern enterprise culture.

The first and most important link in the chain for improving quality must be firmly anchored in the base structure of insurance companies. The other links, which follow on from it and whose business is with the world outside the enterprise, must be of the highest possible quality so as to ensure a smooth flow through the various departments that connect the enterprise system to the end-user it is designed to serve. To put it briefly, I would say that if one really wants to guarantee provision of a quality service, each employee and respectively each office, branch, division, each managerial department must treat the unit next-door (be it branch, division or whatever) as they would a valued customer. The notion of quality of service - I feel I must repeat - needs first of all to be realised within the enterprise or system of enterprises (i.e. group) before it can be offered to the world outside.

If this is not achieved, one runs the risk of having tensions within the firm, reflected in the attitude of those responsible for customer contact, filtering to the outside to the detriment of customer relations. The environment and culture of the enterprise are thus important, and affect to a considerable extent the quality of the service and the public's perception of that service. The roots of a service offered by motivated, courteous, willing and cooperative staff can always be traced back to deep within the enterprise itself.

It becomes essential, therefore, and of great strategic value, to rethink the management philosophy applied in the past by many insurance companies and thereby to develop a new concept of the enterprise based on the notion of quality of service. This is by no means an easy task. For what is needed is to invert the traditional hierarchic pyramid of values within the enterprise, by placing the customer at the top. Next come those responsible for customer contact - and need I stress again that it is the latter who net the customer in the first place, bind him to the enterprise and keep him there. Next as we descend the inverted pyramid come all the other "internal" services, beginning with the technical and administrative departments and so on down until we come finally to those who hold the reins of power and fashion the company's strategy. 
The place at the top of the pyramid belongs by entitlement to the client because ultimately it is he who pays in advance the salaries of the entire staff. We must never forget especially at present - the inversion of the cycle which is the distinguishing characteristic of work in the insurance sector. The positioning of "top management" at the bottom, at the summit, as it were, of the inverted pyramid, is justified in terms of the task entrusted to it : it is "top management's" job to devise and give practical shape to the strategic options which underpin any quality service supplied to the end-user. We should not make the mistake, as all too frequently occurs, of underestimating the difference between on the one hand "offering" a service and on the other "supplying" one.

The time has come for insurance companies which really want to be competitive to begin preparing for 1992 fast instead of just thinking about it. They must rapidly commence an innovative review of their cultural and staff-training procedures, beginning with the echelons bearing the heaviest responsibilities so as to create a trickle effect downwards. We must also be aware that while it is possible to buy technology, and rapidly, training men who are capable of interpreting correctly the new pyramid structure takes a great deal longer. Training, then, becomes a strategic resource of considerable importance that will surely prove useful in bringing about the structural changes which some perhaps would describe as revolutionary but which are in reality when we think about it no more than selfevident.

In the single market with its population of 322 million consumers, more than 4000 insurance companies will be in competition with each other. The behaviour of such companies will certainly not be entirely homogeneous for, as I said earlier, each will have its idiosyncrasies inherited from the past. Moreover, the strategy of an enterprise of international standing may obviously take various forms and will also depend on the kind of markets it operates in. This is why I should like to talk for a few moments about the strategy of the Group of which I am President.

Repeatedly and at different times, I have had occasion to mention, on the one hand, the great geographic diversity which characterises the work of the Generali Group; a feature which, especially from an industrial standpoint, enables us to take advantage of the noncoincidence of technical and economic cycles in the territories in which we operate; on the other hand, I have drawn attention to the long-standing structure of our organisation whose decentralisation has thusfar not only afforded enormous operational flexibility but has also made it more easy to adapt the strategies of each of our subsidiary companies to the prevailing conditions of the markets they serve.

This operational strategy, evolved over a period of more than 150 years, has doubtless borne fruit and has enabled us to build up a group of remarkable dimensions quite capable of competing on an equal footing with the largest operators in the sector. Customers, the press, even our rivals see in Generali a group of long-established international standing operating at the world level. As of now therefore our Group is quite ready for the forthcoming European single market and thereby has a considerable advantage over other insurers.

In the Generali we are all, need I say, most satisfied with the praise and credit which has come our way. Yet this should not absolve us from analysing the situation critically, from checking whether the strategy we have adopted hitherto still applies in the light of the changes I have referred to. If we find it does not, then we shall need to define alternative strategies which will enable us to penetrate the new European and world markets. 
First we are bound to admit that other operators - even if they have not as yet in practice achieved international status through link-ups, mergers and agreements - are preparing to do so thus erroding the advantages of our own position. In recent times French, Swiss, German and English insurers have been particularly active on the markets in France, Spain and Portugal and above all in Italy where 41, out of the 83 national insurance firms that have changed hands over the last five years, are now controlled by foreign companies (more than $30 \%$ of the domestic premium market of that country).

The pull of our market - it should be said in passing - appears in no way to reflect the results of the global technical survey for direct labour in Italy of 1988. Indeed, we are witnessing a gradual deterioration of the claims ratio and have recorded an overall loss of 1'800 billion Italian lira, that is an additional loss of 1'000 billion lira over the previous year. In my view, the need for presence in different countries should in no way be disassociated from positive management results, if we are to acquire the strength we need to guarantee, on the one hand, our customership and, on the other, expansion - which is never easily or rapidly come by, especially on the Italian market.

As I said at the outset, the world economy has undergone changes and this pattern will continue: today's markets no longer resemble those of just a few years ago and the process that has been set in motion is far from complete. Indeed, with the new situation in Eastern countries it is destined to continue for some time to come. For example, on 25th May last year the AB-Generali Company was set up in Budapest - the first joint-venture in the insurance sector between a company in an Eastern European country and Western enterprise. Subsequently, on 18th August in Prague, Generali and the Ceska Statni Pojistovna signed a cooperation agreement. For some time now there has been an agreement with the Soviet State company Ingostrakh whereby both companies cover the risks of Italian enterprises operating in the Soviet Union.

During the 90's we shall have to be paying particular attention to the risks generated by the convergence of economic cycles; such convergence is itself governed by the operations of the multinationals and large conglomerates operating internationally and thus inevitably stimulating world interaction as much in the East as in the West. If we wish to remain in touch with our clients in the 90's we must devise new ways of monitoring the global markets of tomorrow and find new forms of coordination within our Group so as to fashion the existing multitude of companies into a system of insurance enterprises.

As we contemplate these gradual and irreversible changes, as we consider also the international dimensions of individual firms and of the customership of the 90's, we may logically wonder whether the strategy of operational autonomy on a vaste scale that we have thusfar applied to subsidiary companies and peripheral managements, with doubtless satisfactory results, should not be reexamined. Indeed if we are to operate internationally in today's world, presence in markets will no longer suffice; we now need to organise the labour within our system in new ways.

The emerging trend in competition today would seem to indicate the need, on the one hand, for improving the quality of the service we offer (not only during the underwriting phase but also in respect of claims procedures) and, on the other, for a reorganisation of structures which gives priority to the customer and his needs. In this way the insurance sector can offer a coordinated and homogeneous approach to meeting customer requirements. It is precisely through such coordination of its component companies that the 
Generali Group - organised into a network of firms - can offer its customership, locally and internationally, a uniform quality service, not only in national territories but also in the market space of the Community, in third-country Europe as indeed throughout the world.

Each local company, as part of an international network of firms, will be able to offer the domestic market solutions which have already been tried and tested abroad where more advanced insurance markets exist. The competitive edge of such companies locally will thereby be sharpened in an area of great potential where they are known and where their presence will provide capillary attraction. In this way the Group's potential can be fully realised through developing synergies with better results than would be obtained by merely joining together the capacities of individual companies.

This coordination of capacities will make it possible not only to improve the management and regulation of productivity, cost limitation, organisation and distribution, but will enable each company in the Group to achieve a wider underwriting capacity, better reinsurance terms and a higher retention rate, far beyond what would have been possible had it operated in isolation. Uneconomic competition within the Group in respect of the same account or client will thus be avoided.

The aggregate of the advantages I have just described (management, reinsurance on better terms combined with increased capacity and retention) will mean that each company in the Group will be able to cut costs and so offer its clientele located throughout the globe more competitive prices. Ultimately, each company member of the Group in the daily challenge it faces at the domestic, European or world levels will become more competitive and still able to apply the technical principles that have come down to us from the past ; even if - as is my personal belief - in years to come, competition in the insurance sector will be keener in the area of service than in that of price.

The new deal which Generali is planning to offer end-users through provision of a coordinated, homogeneous and quality service (as regards underwriting, claims settlement and assistance) dovetails perfectly with the demand coming from an increasingly internationally mobile customership. Indeed, not only will enterprises transcend national boundaries in part because of the volatile nature of markets, but, with the commitment of the twelve member states of the EEC to remove barriers to intracommunity movement of persons, capital, goods and services between now and the end of 1992, physical persons themselves as well, as they travel from country to country, will be calling for a functional service that goes beyond the confines of the Community. The effects of this development, as I have already said, will begin to be felt in our sector well before the scheduled datelines.

The formidable growth of the services sector in Europe, stimulated by the emergence of new modes of distribution as well as by the imminence of the 30th June 1990, dateline for the free circulation of both capital and insurance services, will have marked repercussions in our sector. The latter will be effected not only because as of that date any insurer established in any Community country will be entitled to operate on the territories of other Community countries but also because certain insurance companies will be having to compete with other Community firms which make use of alternative channels of distribution. Within this process, which has now been set in motion and whose purpose is the achievement of that harmonisation which will make possible the creation of a single market, must be incorporated - and on this we must insist - standards which enable operators 
to compete on an equal footing and which will minimize the possibility of distortion of competition. It should be noted in this connection that the current pattern of distribution among European partners is by no means homogeneous, since its structure and flexibility are apt to vary. It is therefore highly desirable that the remarkable boom in the supply of insurance products, brought about in certain EEC countries by the use of the so-called alternative channels, be reproduced in the other member countries. At the same time it must be remembered that in several countries traditional channels are nevertheless destined to remain the principal modes of distribution.

While retaining the golden rule of "professionalism in the service of the enduser", other modes of distribution must be found for bringing insurance products to an ever increasing number of customers. With carefully assessed initiatives better use could be made of companys' collective potential by developing synergies for the acquisition of market shares which would otherwise remain virtually inacessible and consequently neglected. Customerships could thereby be expanded and a much greater overall result achieved than would be possible by the mere accretion of the individual capacities of the firms concerned.

The recent founding in Italy at Mogliano Veneto, near Venice, of a Generali Group School is of great strategic importance to us and will prove decisive, I am sure, for the competitivity of our company. The School is recruiting specially trained staff and also benefits from the expertise of certain active professionals within the Group who thus ensure continuity. Moreover, specific, systematic and continuous training will enable us to foster in our staff ability to cope with the changes generated by the agitated world of today. It will enable us also firmly to establish a certain pattern of behaviour characteristic of the Group's image. The School which exists essentially for training Group staff is in point of fact geared to our Italian and international customerships, the end-users of the high quality service we seek to provide. More specifically, through fostering a common culture our School will be furthering coordination of training - not only at the national level - by providing selective highquality courses for administrative and technical management staff. The School will also be responsible for organising technico-professional in-service training for agents, sub-agents, salemen and claim-assessors with a view to improving and giving homogeneity to the service we offer our clients throughtout the world.

At a time of confusion and disorder (the 1993 market) with clear signs of a trend towards flexibility, the existence of a mix of enterprise cultures - which up to now has frankly been to our advantage - may prove to be a source of structural viscosity which in turn may well hamper strategic innovations. It therefore seems appropriate, not to say necessary, to lower the existing culture profiles of the enterprises within the Group, while preserving even so the identities of individual companies. In this way it should be possible, through a suitable process of osmosis, to forge a Group culture. The Generali Group, once structured into a network of enterprises, would then be able to increase its profile and strengthen its ties abroad. Provided that it can, from within its own structure, be perceived as a coherent entity.

In this day and age size will not suffice: strategic management must be made to improve the coordination of the heart, mind and limbs by fostering a common culture, by encouraging people's ability to think, by establishing a common system of values, by devising thuswise optimal strategies for incentive and feed-back. In achieving these ends 
we must rely heavily on certain tools which will help to build bridges between people who, by reason of the tasks entrusted to them by the enterprise, cannot be physically close. I am thinking in particular of the "House Organ" issued by the Parent Company and the Generali Group's "Newsletter" which is currently in circulation.

We are quite sure that our willing commitment to fostering culture, instruction and professional training, all be they costly, will not be in vain. Quite to the contrary, the individual will find therein opportunities for further "growth" and the Group a sure source of "profit." 